\title{
Gamificação na educação patrimonial: Escola Álvaro Guião (SP-BR)
}

\author{
Gamification in patrimonial education: Escola Álvaro Guião (SP-BR)
}

\author{
Juliana de Mello Crivelli \\ Instituto de Arquitetura e Urbanismo da \\ Universidade de São Paulo, Brasil \\ juliana.crivelli@usp.br \\ Simone Helena Tanoue Vizioli \\ N.elac - Instituto de Arquitetura e Urbanismo da \\ Universidade de São Paulo, Brasil \\ simonehtv@sc.usp.br
}

\begin{abstract}
This article integrates works developed in the Núcleo de Apoio em Pesquisa em Estudos de Linguagem em Arquitetura e Cidade (N.elac) of the Instituto de Arquitetura e Urbanismo da Universidade de São Paulo, and aims to evaluate the contribution of the game as an auxiliary instrument to the patrimonial education (Horta, Grunberg \& Monteiro, 1999). Games present themselves as one of the constitutive elements of culture, and many are the authors that discuss the theme. Between them, Huizinga, 2000; Callois, 1990 and Brougère, 2004. The developed game is an interactive narrative inside a building listed as herritage by the Conselho Municipal de Defesa do Patrimônio Histórico, Arquitetônico, Artístico e Turístico (CONDESPHAASC): the Escola Estadual Dr. Álvaro Guião.
\end{abstract}

Keywords: Gamificação; Educação Patrimonial; Meio digital; Jogo Digital; Escola Álvaro Guião.

\section{Introdução}

Este artigo compõe os trabalhos desenvolvidos pelo Núcleo de Apoio em Pesquisa em Estudos de Linguagem em Arquitetura e Cidade (N.elac) do Instituto de Arquitetura e Urbanismo da Universidade de São Paulo, cujo objetivo tem em sua premissa a contribuição do jogo como instrumento auxiliar na educação patrimonial. Integra um Projeto de Cultura e Extensão da USP que vem sendo desenvolvido desde 2012 e que busca estimular o conhecimento sobre edifícios de valor arquitetônico, histórico e cultural do Município de São Carlos, por meio da manipulação de Sistemas Lúdicos Interativos.

A pesquisa é subdividida em três eixos: 1) blocos tridimensionais, 2) jogos educativos em meio digital e 3) modelos tridimensionais em dobraduras em papel. Esses jogos permitem que o jovem problematize dados de sua realidade local e, assim, inicie a estruturação de um posicionamento crítico na comunidade. Especificamente sobre os jogos em meio digital, em 2012, foi desenvolvido um jogo de quebra-cabeça; em 2014 os pesquisadores criaram um jogo de sete erros e em 2015/2016 foi elaborado um jogo narrativo interativo - objeto específico deste artigo.

Neste contexto, este trabalho utiliza-se da gamificação, que parte do princípio de associar elementos de jogos a situações que previamente não seriam consideradas como jogo, de modo a criar um ambiente que estimula a interação do indivíduo (Busarello, Ulbricht, Fadel in Fadel, 2014. O jogo elaborado trata de uma narrativa interativa que se passa na Escola Estadual Dr. Álvaro Guião, situada no Município de São Carlos, SP, Br.
Educação Patrimonial

A Educação Patrimonial surge no Brasil em meio a importantes discussões da necessidade de aprofundar-se o conhecimento e a preservação do Patrimônio HistóricoCultural. Em 1983 iniciaram-se efetivamente as ações de Educação Patrimonial por ocasião do $1^{\circ}$ Seminário sobre 0 "Uso Educacional de Museus e Monumentos", no Museu Imperial de Petrópolis, RJ. Eis o princípio básico da Educação Patrimonial:

\begin{abstract}
Trata-se de um processo permanente e sistemático de trabalho educacional centrado no Patrimônio Cultural como fonte primária de conhecimento individual e coletivo. A partir da experiência e do contato direto com as evidências e manifestações da cultura, em todos os seus múltiplos aspectos, sentidos e significados, o trabalho de Educação Patrimonial busca levar as crianças e adultos a um processo ativo de conhecimento, apropriação e valorização de sua herança cultural, capacitando-os para um melhor usufruto desses bens, e propiciando a geração e a produção de novos conhecimentos,num processo contínuo de criação cultural (Horta, Grumberg, Monteiro, 1999, p. 06).
\end{abstract}

Segundo Horta (1999) o processo de Educação Patrimonial, o qual considera esta como "instrumento de alfabetização cultural", "leva ao reforço da autoestima dos indivíduos e comunidades e à valorização da cultura brasileira, compreendida como múltipla e plural", enquanto promove a comunicação e interação entre a comunidade e os agentes responsáveis pela preservação dos bens culturais, possibilitando a troca de conhecimentos e fortalecendo a preservação do patrimônio. 
Assim, a Educação Patrimonial possibilita a interpretação dos bens culturais, tornando-se um instrumento importante de promoção e vivência da cidadania, gerando a responsabilidade na busca, na valorização e preservação do Patrimônio.

\section{A Escola Álvaro Guião}

Fundada em 1911, a Escola Normal Secundária de São Carlos foi precursora das faculdades de filosofia, formando professores para Grupos Escolares e demais escolas para formação de professores. Inicialmente, foi instalada no prédio da Rua José Bonifácio, hoje, EEPG Eugênio Franco. Em 1913, foi lançada a pedra fundamental do novo edifício, que abriga até hoje a maior Escola Secundária de São Carlos. Projetado pelo arquiteto alemão Carlos Rosencrantz e construído pelo engenheiro Raul Porto juntamente com o mestre de obras Torello Dinucci, o prédio, em estilo eclético, apresenta elementos de influência art nouveau e neo clássico. Foi construído no "alto da colina" e ocupa um quarteirão entre as atuais ruas Padre Teixeira e São Sebastião e as avenidas São Carlos e D. Alexandrina e inaugurada em 1916.
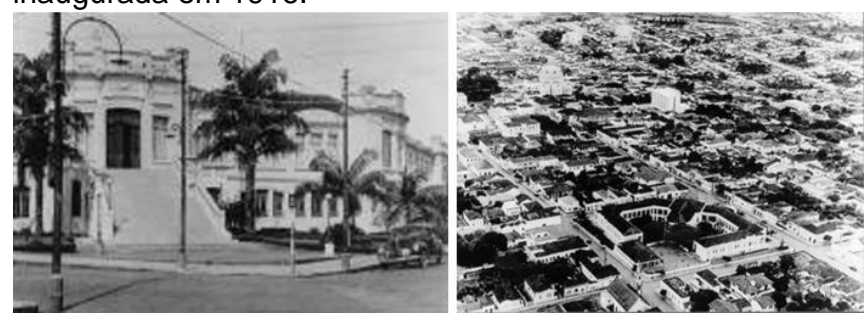

Figura 1: Vista aérea da Escola Normal em foto de 1960 e escadaria da entrada principal. Fonte: Morila, 2005.

O edifício foi tombado em 1985 pelo Conselho Municipal de Defesa do Patrimônio Histórico, Arquitetônico, Artístico e Turístico de São Carlos (CONDESPHAASC). Grande parte do material de acabamento da obra foi importado. O piso do saguão é francês, as soleiras das portas são de mármore italiano, os lustres de cristal Baccarat e a mobília em madeira trabalhada. Os laboratórios, à época, ofereciam maquinário e vidraria vindos da Europa.

\section{O jogo}

Os jogos apresentam-se como um dos elementos constitutivos da cultura, e vários são os autores que se debruçam sobre o tema, entre eles Huizinga, 2000; Callois, 1990 e Brougère, 2004. Caillois (1990) coloca em evidência a dimensão socializante dos jogos devido ao fato de que essas atividades possuem um potencial de coletividade inerente a elas. Atividades lúdicas também podem interferir na aprendizagem e formação da criança. A autora Edda Bomtempo (1999) afirma a importância dessas atividades no desenvolvimento das crianças, através do estudo das teorias do filósofo Jean Piaget:

"Para Piaget (1951), o jogo é fator de grande importância no desenvolvimento cognitivo. O conhecimento não deriva da representação de fenômenos externos, mas sim da interação da criança com o meio ambiente. O processo de acomodação e assimilação é meio pelo qual a realidade é transformada em conhecimento. No brincar, a assimilação predomina e a criança incorpora o mundo à sua maneira sem nenhum compromisso com a realidade. Neste sentido, brincar é parte ativa, agradável e interativa do desenvolvimento intelectual." (Bomtempo, 1999, p.61)

Segundo Albuquerque e Fialho (2010), interatividade também pode ser considerada como um fator positivo presente nos jogos eletrônicos, o que contribui para a adaptação à rapidez em que ocorrem as mudanças contemporâneas. Mesmo jogos digitais bastante simples propiciam interatividade e aprendizagem, pois induzem o usuário à experimentação através da tentativa e erro, caracterizando um processo de aprendizado autônomo.

Meio digital

Meira (2003) afirma que existe uma forte relação entre jogos digitais e as imagens. Segundo a autora, os jogos virtuais podem ser vistos como tentativas das crianças de "brincar com imagens". A feitura desses tipos de jogos ocorre por meio do desenho. Logo, a utilização de um desenho voltado ao público-alvo com o uso de cores torna-o mais atrativo as crianças, influenciando na usabilidade do jogo, assim como outros fatores, dentre os quais o desafio, que pode tornar o jogo mais interessante. Uma boa usabilidade é fundamental para tornar o jogo lúdico ao usuário.

Os desenhos que compõem a narrativa do jogo deste artigo foram feitos em meio digital a partir de fotografias com o auxílio de softwares de imagem, Pads digitais e mesas digitalizadoras (Cintiq). Foi utilizado o software SketchBook Pro da Autodesk em uma mesa digitalizadora de 23" (Cintiq) para a feitura das ilustrações. O programa disponibiliza diversos recursos de desenho e propicia 0 trabalho desenhos a mão livre sobre fotografias, através da interação de camadas. Priorizou-se a linguagem gráfica do desenho feito a mão livre, na busca de uma imagem humanizada e mais simples, objetivando a familiarização da criança com o edifício.

\section{Stencyl}

O Stencyl é um software que utiliza a linguagem Haxe por trás do seu sistema de organização do código em blocos encaixáveis e disponibiliza a exportação do projeto para plataformas móveis, como iPads, em conjunto com o software XCode. Por já ser voltado ao desenvolvimento de jogos, o programa possui algumas funcionalidades que são utilizadas em grande parte dos jogos, como a importação de imagens para sprites e a animação automáticas destas. Consequentemente, o uso do Stencyl facilita o desenvolvimento de jogos para iniciantes.

Um projeto criado em Stencyl possui cenas e atores, que podem ter comportamentos e eventos atribuídos a eles. Uma cena é o ambiente em que as ações do jogador ocorrem e os atores, os objetos em cena com os quais o jogador irá interagir. No programa, através de interfaces gráficas, descreve-se características de cada comportamento, por exemplo, no comportamento de um ator $\mathrm{X}$ : quando um objeto, deste tipo de ator, é colocado em uma cena, se ele receber um toque, seu nome é adicionado em uma lista, é tocado um efeito sonoro e ele é removido da cena. 
SIGraDi 2016, XX Congress of the Iberoamerican Society of Digital Graphics

9-11, November, 2016 - Buenos Aires, Argentina

As ações de um comportamento são definidas em blocos de comandos encaixáveis e executados em ordem, assim que o comportamento é acionado. Por trás de cada bloco há linhas de código na linguagem Haxe, porém, ao usuário comum não é necessário o aprofundamento no código a não ser que uma modificação nos blocos já existentes seja desejada. Os blocos são divididos em categorias de acordo com o tipo de ação que executam. Há por exemplo, blocos que lidam com lógica, matemática simples e comandos de repetição, outros lidam com manipulação de sons e outros ainda com atributos customizáveis. Cada bloco possui suas particularidades, mas no geral eles possuem um alvo para o qual suas ações são direcionadas: o próprio ator, o último ator criado, o último ator colidido, entre outros.

\section{Metodologia}

Divide-se a abordagem em 4 fases: fundamentação teórica, uma revisão dos temas sobre educação patrimonial, jogos (digitais), computação e arquitetura; desenvolvimento do produto, no qual foi utilizado o programa Stencyl, um software para desenvolvimento de jogos, escolhido pelo fácil aprendizado do programa e por possibilitar o jogo em tablets móveis; na fase da usabilidade, os protótipos foram testados com crianças do ensino fundamental da Escola. As respostas obtidas foram utilizadas como feedback. Após a revisão, tem-se a capacitação dos professores para a utilização do jogo no processo educativo, tornando-os

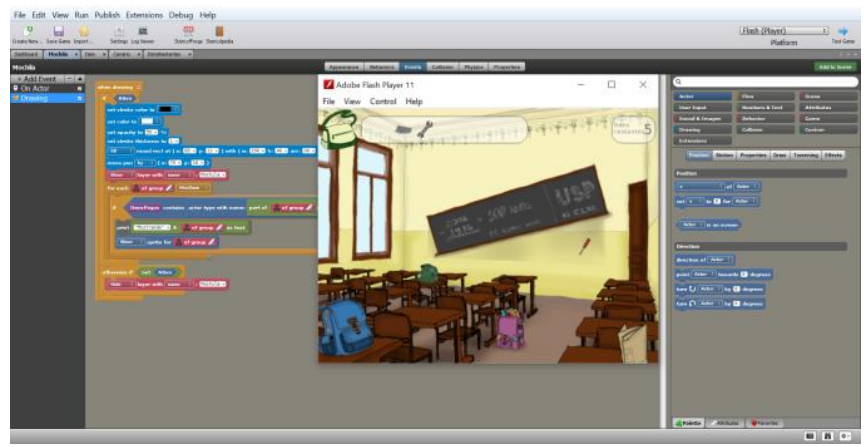

multiplicadores do conhecimento produzido pela pesquisa.

Figura 2: Tela do jogo desenvolvido dentro do Stencyl a partir de um desenho de uma sala de aula da Escola Álvaro Guião. Fonte: Crivelli, 2016.

O jogo se passa dentro da própria Escola Dr. Ávaro Guião, iniciando-se com um pequeno vídeo que conta uma hitória fictícia, em que a personagem retorna a 1916, ano de inauguração do edifício. Três ambientes, sendo eles o saguão, o auditório e uma sala de aula, podem ser explorados e seus cenários são desenhos humanizados digitais, realizados com o auxílio de uma Cintiq. Em cada sala, o aluno pode interagir com os objetos, revelando peças necessárias para o retorno a 2016. A navegação entre os ambientes se dá através de plantas do primeiro e segundo pavimento do edifício, criando assim um contato com a linguagem arquitetônica que pode ser explorado pelo educador. Além disso, o jogo apresenta em diversos momentos informações textuais acerca da história do edifício. Ao encontrar todas as peças, o jogo encerra-se com um vídeo enaltecendo o centenário da Escola.

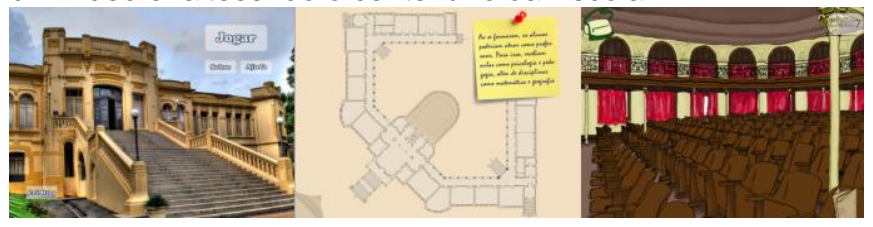

Figura 3: Telas do jogo da esquerda para a direita: menu inicial, navegação entre as salas, auditório. Fonte: Crivelli, 2016.

\section{Dificuldades encontradas}

Desde o ínicio desta série de trabalhos, em 2012, a proposta para a família de jogos educativos em meio digital possuía iPads como sua plataforma base. Houve, porém, grande dificuldade em relação à codificação de aplicativos para o tablet. Programação e arquitetura são áreas que tradicionalmente não são ensinadas em conjunto e muito tempo foi gasto nos projetos anteriores com a aquisição de conhecimentos básicos de programação e na busca de uma tecnologia que melhor se adequasse ao objetivo da pesquisa.

Inicialmente, optou-se pelo uso do Processing, uma linguagem de programação que se auto-intitula voltada para artistas. O quebra-cabeça desenvolvido funciona apenas em computadores comuns, como um arquivo executável. O próximo jogo da série utilizou o software GameSalad para intermediar a programação. O resultado foi um jogo hospedado em um servidor de terceiros, que poderia ser acessado em diversas plataformas, inclusive iPads. Somente na terceira edição do projeto, a atual, o aplicativo desenvolvido pode ser executado diretamente no iPad, o que permite a disponibilização do aplicativo na loja de aplicativos da Apple, a App Store. Com isso, o jogo desenvolvido tem o potencial de alcançar um público maior, além dos locais de aplicação física da pesquisa.

A ferramenta escolhida para a confecção deste terceiro jogo, apesar de ter permitido um resultado final positivo, impôs uma série de dificuldades. Por não ser inteiramente voltada ao desenvolvimento mobile da Apple, nem todas as funcionalidades que o software possui estão disponíveis para iPads. Por exemplo, um tempo equivalente ao tempo de programação do core do jogo foi despendido para contornar a falta de um player de vídeos para iPad. Foi necessário transformar o filme criado para a cena de introdução e a cena de encerramento do jogo por uma série de imagens estáticas, em um número reduzido de frames e realizar manualmente a transição entre cada um deles. Outro problema encontrado foi o número reduzido de opções de alvos para os blocos de comandos do Stencyl. Como consequência, a lógica de programação precisou ser adaptada para contornar as imposições do software.

O Stencyl fornece a opção de teste direto no aparelho escolhido, no caso, o iPad. Porém, antes de realizar a simulação é preciso utilizar um segundo software, o XCode, uma ferramenta que funciona apenas em computadores com o sistema operacional da Apple, e nele criar um projeto de nome idêntico ao projeto do Stencyl e testá-lo, mesmo que vazio, em um aparelho já autorizado para executar 
SIGraDi 2016, XX Congress of the Iberoamerican Society of Digital Graphics

9-11, November, 2016 - Buenos Aires, Argentina

aplicativos através de um cabo USB e somente após a realização desse processo é possível testar 0 jogo desenvolvido em Stencyl no aparelho. A documentação não é clara em relação a todos os procedimentos necessários para testes em plataformas da Apple e várias informações estão desatualizadas neste tópico. $O$ processo de programação e testes exigiu uma exploração e pesquisa dentro do software escolhido para a criação do jogo.

Análise dos dados

No dia 11 de junho de 2016 foi realizado um teste-piloto em uma feira cultural aberta ao público, ocorrida na própria escola Álvaro Guião. O teste foi aplicado a 17 pessoas, as quais responderam um questionário onde buscou-se avaliar alguns aspectos, tais como: a eficácia do jogo como ferramenta auxiliar no processo de educação patrimonial; a motivação e o nível de atenção do jogador; a dificuldade e desafio que, em conjunto com o tempo necessário para completar o jogo e, por fim, a qualidade gráfica das imagens contidas no jogo.

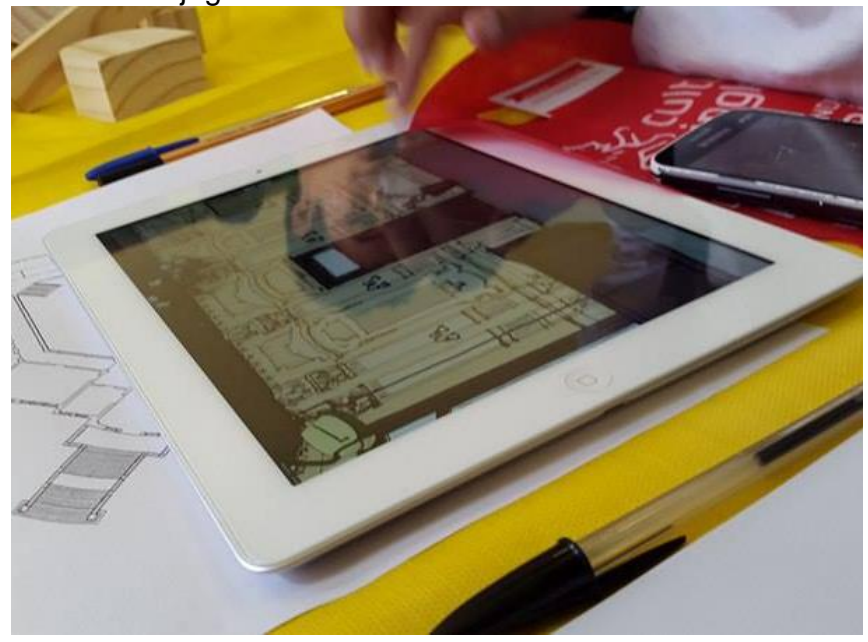

Figura 4: Aplicação do jogo na feira cultural da E.E. Dr. Álvaro Guião. Fonte: Crivelli, 2016.

Os 17 participantes possuíam idades entre 11 e 16 anos, sendo que apenas um deles não conhecia o edifício da Escola. Por meio do pre-teste foi possível observar um maior interesse e concentração dos jogadores quando o fizeram em duplas ou trios.

Uma dificuldade apurada durante o teste foi a navegação entre os ambientes, a qual se apresentou de forma inversamente proporcional à idade dos participantes: A navegação se dava por meio de uma planta do edifício e poucos possuíam algum conhecimento prévio de linguagem arquitetônica.

As imagens receberam avaliações positivas e os participantes conseguiram associar os desenhos com os ambientes reais da escola. Segundo um dos participantes, a possibilidade de reconhecer as cenas do jogo em locais reais fez com que ele quisesse explorar mais telas de jogo além daquelas disponíveis. De fato, para uma parcela dos jogadores, concluímos que o jogo desenvolvido é curto: acima de 14 anos o tempo médio gasto para alcançar a cena final foi de 2 minutos, enquanto jogadores de 12 anos levaram o dobro do tempo. O jogo não foi considerado difícil e ocorreu um empate entre aqueles que o classificaram como fácil e médio, com $47 \%$ cada opção. A dificuldade do jogo, porém, não foi um empecilho. Em uma outra pergunta $59 \%$ dos participantes julgaram o nível de dificuldade ótimo e $35 \%$ consideraram-no bom. Uma análise dos dados acima em conjunto com os dados obtidos a respeito da motivação durante 0 jogo, podemos considerar 0 engajamento satisfatório, um fator positivo na associação entre jogos e aprendizado.
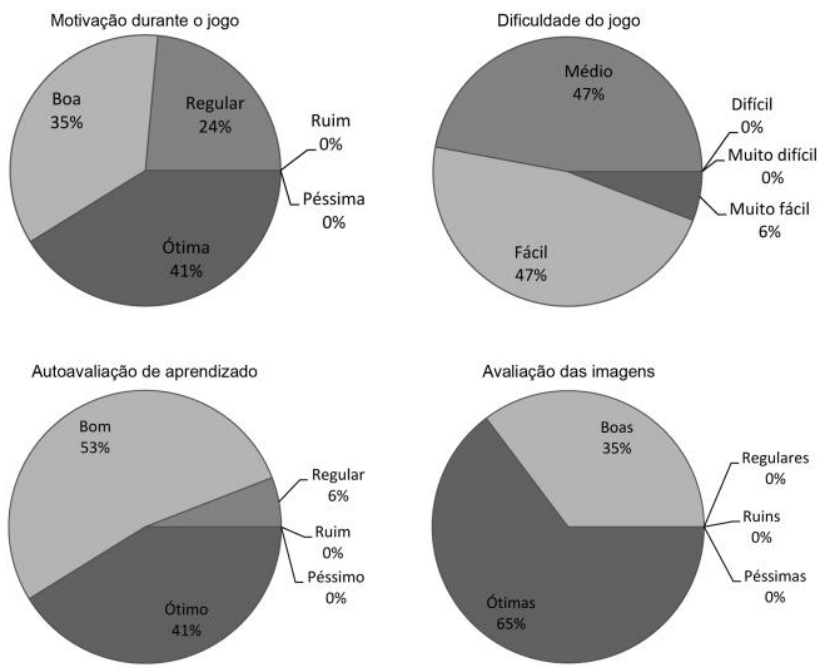

Figura 5: Gráficos gerados a partir de dados obtidos na aplicação. Fonte: Crivelli, 2016

O pre-teste é uma importante etapa pois permite aprimorar o desenvolvimento do jogo bem como a sua aplicação. Porém, ainda nesta fase, com base nos resultados levantados, comprova-se que o jogo é um aliado na educação, principalmente junto ao público infantil e jovem. Em um momento pautado pela velocidade da informação, o jogo alia o encantamento digital do usuário com a propagação de conhecimento.

\section{Conclusão}

A linguagem de programação apresenta-se como uma metodologia projetual que pode ser utilizada para representar e ampliar a divulgação do conhecimento em arquitetura, especificamente como ferramenta de educação patrimonial. Os jogos digitais são uma forma eficiente de transmissão do conhecimento ao público infantil tendo em vista o nível de atenção que a interação com um meio lúdico proporciona. Embora a importância do produto seja clara, merece destaque o processo do seu desenvolvimento: a gamificação, neste trabalho, trata-se de um processo de aprendizagem que abrange conhecimentos técnicos, como programação, game design, desenho (das cenas) e conhecimentos teóricos que incluem psicologia motivacional e cognitiva, além de história e arquitetura patrimonial. A gamificação se mostra, portanto como um campo multidisciplinar profícuo na área de educação patrimonial. 
SIGraDi 2016, XX Congress of the Iberoamerican Society of Digital Graphics

9-11, November, 2016 - Buenos Aires, Argentina

Espera-se que sua aplicação nas escolas resulte na Bomtempo, Edda. (1999). Brinquedo e Educação: na Escola e no formação de reflexões pelo aluno e na valorização dos bens culturais, aqui entendida como o município de São Carlos. Esses jogos devem possibilitar a assimilação do conhecimento em arquitetura patrimonial criando as bases para a formação de uma consciência histórica, sem a qual a preservação do patrimônio não é possível. Dessa forma, ao auxiliar na educação patrimonial e no ensino das crianças, os jogos possibilitam preservar o patrimônio arquitetônico para as gerações futuras.

\section{Agradecimentos}

Ao Instituto de Arquitetura e Urbanismo (IAU-USP) pelo apoio à pesquisa, à Pró-Reitoria de Cultura e Extensão Universitária (PRCEU-USP) pelo financiamento da bolsa de estudo, ao CNPq pelo financiamento dos equipamentos digitais, ao Núcleo de Apoio à Pesquisa em Estudos de Linguagem em Arquitetura e Cidade (N.ELAC) pela infraestrutura disponibilizada para a realização dos trabalhos, à Escola Estadual Dr. Álvaro Guião.

\section{Referências}

Albuquerque, R. M., \& Fialho, F. A. P. (2010). A interatividade e o potencial de aprendizagem através dos jogos eletrônicos. Encuentro Latinoamericano de Diseño em Palermo. Actas de Diseño no9, v. 9, 175-178.

Arce, A. (Org); Nery, A. C. B. (Org). (2011). Ideias pedagógicas em movimento: Produção de saberes na Escola Normal Secundária de São Carlos. São Carlos: EdUFSCar.

Brougère, G. (2004). Brinquedos e Companhia. São Paulo: Cortez.

Lar. Psicologia Escolar e Educacional, Abrapee / São Paulo, v. III, n.1, p. 61-69.

Caillois, R. (1990). Os Jogos e os Homens. Lisboa: Cotovia.

Fadel, L. M. (Org) et al. (2014). Gamificação na educação. São Paulo: Pimenta Cultural.

Flusser, V. (2008). O Universo das Imagens Técnicas. Elogio da Superficialidade. São Paulo: Annablume.

Horta, M. de L. P., Grumberg, E., \& Monteiro, A. Q. (1999). Guia Básico da Educação Patrimonial. Brasília: Instituto do Patrimônio Artístico Nacional, Museu Imperial.

Huizinga, J. (2000). Homo Ludens: O Jogo como Elemento de Cultura. São Paulo: Perspectiva, 4⿳亠丷a edição.

Meira, A. M. (2003). Benjamin, os brinquedos e a infância contemporânea. Psicologia \& Sociologia. n.2, vol.15, 74-87. Universidade Federal do Rio Grande do Sul.

Morila, A. P. (2005, Setembro). Um monumento na avenida: a escola normal de São Carlos. Revista HISTEDBR On-line, Campinas, n.19, p. $40-62$, ISSN: $1676-2584$

Santaella, L. Games e Comunidades Virtuais. (2004) In: Hiper> Relações Eletro/ Digitais. Porto Alegre: Santander Cultural, Retirado de:

http://www.canalcontemporaneo.art.br/tecnopoliticas/archives/00033 4.html

Santiago, R. P. (2011). Jogos e Processos de Projeto: Diálogos Possíveis. Artigo. Faculdade de Engenharia Civil, Arquitetura e Urbanismo, Universidade Estadual de Campinas. XV Congresso SIGRADI.

Stencylpedia - Table of Contents. (2016). Stencyl.com. Retirado 16 de janeiro 2016, de http://www.stencyl.com/help/toc/ 